reduction in the urine to normal, and the disappearance of liver tenderness. Thereafter convalescence should last about twice the period spent in bed. The patient should be advised to abstain from alcohol for one year. It is also worth seizing the opportunity, if it presents, of maintaining the patient's disinclination to smoke instead of regarding his first cigarette as another milestone, albeit an unworthy one, of recovery. As with bed rest, so should the diet be adjusted to the individual's needs. The person who is nauseated by fatty food is best put on a light diet high in carbohydrate, whereas the patient who wants fat should be allowed it. A controlled dietetic study has in fact shown that patients receiving a diet higher in fat regained their weight more rapidly, and bromsulphthalein tests reverted to normal sooner, presumably because of the higher number of calories assimilated. ${ }^{\circ}$ On the other hand, the diet and the intake and output of fluids and electrolytes in the patient with acute fulminant hepatitis need to be carefully balanced along the more rigid regime appropriate to patients in acute hepato-cellular failure, and neomycin may need to be given by mouth. Corticosteroids should be reserved for the severely ill and toxic patient whose serumbilirubin level continues to rise.

Control of the disease ultimately lies in better methods of preventing both infectious and serum hepatitis. Infectious hepatitis is an enteric infection, spread in the same way as poliomyelitis and typhoid fever. By analogy with these diseases maintenance of hygienic sanitation is of paramount importance. But great success attended the introduction of vaccination for poliomyelitis and of chloramphenicol for typhoid fever. While we lack such an effective treatment for infectious hepatitis the next best is human serum gamma-globulin, of which supplies are scarce. If given soon after exposure to infection and up to six days before the onset of symptoms, the course of the disease is modified. The patient does not develop frank jaundice but instead suffers a milder anicteric subclinical hepatitis. He may even remain free of symptoms, but laboratory tests will give evidence of liver-cell dysfunction. Gamma-globulin is useful for changing the course of an epidemic, or modifying the severity of infection in children, in debilitated patients, and during pregnancy.

The prevention of serum hepatitis lies in a scrupulously aseptic technique for all injections and the avoidance of the unnecessary use of human blood or products of it. Every piece of apparatus that penetrates the skin should be sterilized by autoclaving or in dry heat at $180^{\circ}$ C: for one hour. Sterilization with ethylene oxide gas may be necessary for bulky apparatus. ${ }^{7}$ Chemical disinfectants are unacceptable alternatives. Disposable syringes, needles, lancets, and transfusion sets are clearly preferable. The incidence of healthy carriers of the serum hepatitis virus in the United States has been estimated as 2 to $3 \%,{ }^{8}$ and their detection is well-nigh impossible. Thus the repeated use of a small number of selected blood donors known to be free of infection is preferable to a large pool in which there may be carriers of the virus. As a result of their careful survey in Bristol Dr. Bothwell and his colleagues were able to provide details of families with hepatitis to the Blood Transfusion Service, which will be of inestimable value in the local programme for screening prospective donors.

\section{CORONERS' DUTIES}

The itch to destroy what is old merely because it is old is not unknown. The English Coroners' System, which has existed since the twelfth century, has not escaped such attention. Yet, to quote a recently published memorandum by the Coroners' Society, it is " a good example of survival by adaptation." The system serves " not only to prevent and discourage ill-disposed persons from doing away with their relations and their neighbours ... but also to protect innocent persons from the suspicion and odium which an unexplained death can so easily throw upon them." The council of the Coroners' Society recognizes that there is room for further adaptation, and its memorandum contains several important recommendations for the improvement of the system. The main proposals relate to the number of coroners' jurisdictions, curtailment of the number of jury cases, the abolition of viewing the body by the coroner, reporting deaths to the coroner, assistance by pathologists, and public mortuaries.

The competent conduct of an inquest, and indeed the performance of the coroner's duties in general, demand experience in addition to skill. Some coroners "cannot hope for enough experience for proper efficiency." A reduction in the number of coroners' districts would remedy this state of affairs and was advocated recently in a report by a special committee of the British Medical Association. ${ }^{2}$ The council of the Coroners' Society proposes that districts shall be merged whenever the opportunity arises through vacancies in the existing coronerships. The revised jurisdictions should be based not on population but on the number of deaths reported in a year to the coroner, for the council finds this to be a more accurate gauge of work. Its preference for a gradual change by merger as and when the opportunity occurs is likely to take some years to yield effective improvement, for many difficulties stand in the way, as

\footnotetext{
Memorandum prepared by Coroners' Society of England and Wales (apMedico-legal Investigation of Deaths in the Community (England and Wales), Brit. med. J. Suppl.. 1963, 1, 220.

3 Havard, J. D. J., The Detection of Secret Homicide, 1960. London.
} 
J. D. J. Havard has shown. ${ }^{3}$ But though drastic changes in a well-established system could, do more harm than good it might be possible to effect some mergers forthwith by consent if subject to reasonable compensation for loss of office.

The reduction of the number of cases in which a jury is required could safely follow the appointment of experienced coroners. The coroner should retain the right to exercise his discretion to summon a jury. But he should be obliged to do so only when the death is suspected to have been due to a criminal act or when the inquest concerns the death of any person under lawful detention.

The present obligation of a coroner to view the body in order to have jurisdiction to hold an inquest, a relic of ancient practice, leads to waste of time. He should simply retain the right to do so at his discretion. Whether the coroner (or his officer) should have a legal right to enter private premises in order to have access to the body, as the council suggests, is more debatable. It is worth noting that legislation already grants officials of several kinds this right, and it might reasonably be thought that extension of it should be granted only when it is clearly shown that lack of it obstructs the coroner in the proper performance of his duties.

The council recommends that it should be the statutory duty of a doctor to notify the coroner of " all deaths other than those known to be due to natural causes, seen and treated by a registered medical practitioner within fourteen days before death." Many would agree with this, and at the same time "attendance" could be defined in relation to certification of cause of death ; it might suitably be, as the council recommends, "at least twice within fourteen days before death." It would be opportune also to consider making it obligatory for the doctor to inspect the body before he issues a medical certificate of cause of death. Moreover, when the cause of death is not known it should not be lawful to perform a post-mortem examination except on the instructions of a coroner.

The council pays generous tribute to the value of assistance by skilled pathologists. "The pathologist is a most important member of the coroner's team. . . . The post-mortem examination is the core of the medicolegal investigation and should never be omitted without very good reason. Only in the most exceptional circumstances should an inquest be held without post-mortem examination." The council considers the choice of pathologist must be left to the coroner. At the same time mortuaries need improving, as has been recognized for some years, ${ }^{4}$ for some are in a deplorable condition. The Coroners Rules of 1953 laid down the minimum requirements for post-mortem examinations in mortuaries. So far these have been little more than pious hopes, for the coroner has no power to compel their provision. It is in the public's interest to have not only a body of competent forensic pathologists but also satisfactory conditions under which their skilled work can be performed.

\section{CLOSTRIDIUM WELCHII FOOD-POISONING}

Since 1953, when $\mathrm{Cl}$. welchii was accepted and fully described as a cause of food-poisoning, the clinical picture and epidemiology of this disease have become increasingly clear. There is severe diarrhoea and abdominal pain, usually without vomiting, beginning eight to 24 hours after a meal ; serologically identifiable strains will be found in the stools from a high proportion of patients and also in large numbers in the food. Data for food-poisoning published yearly ${ }^{1}$ indicate that in the great majority of outbreaks due to $\mathrm{Cl}$. welchii the vehicle of infection is found. Almost without exception it is meat with a history of storage at a warm temperature for at least one and a half to two hours after cooking. Thus the growth of the organism is encouraged by long. slow cooling, by lengthy warming-up procedures, or by a combination of both these phenomena, as noted by Dr. W. H. Parry elsewhere in this issue (p. 1616). In his paper Dr. Parry draws attention once again to the classical faults in the large-scale production of meat meals which have led so often to $\mathrm{Cl}$. welchii food-poisoning.

The strains of $\mathrm{Cl}$. welchii usually involved produce heat-resistant spores most of which survive boiling for at least one hour and often longer. The organisms are not uncommonly present in human and animal intestines, and raw meat is frequently contaminated before it reaches the kitchen, probably from animal sources. The heating during cooking "activates" the spores, so that during cooling they germinate promptly into vegetative cells. ${ }^{2}$ The newly emerged bacilli multiply actively but do not readily form spores again on the cooked meat or in culture. $\mathrm{Cl}$. welchii grows well at temperatures up to $50^{\circ} \mathrm{C}$., the optimum appearing to be $43^{\circ}-47^{\circ} \mathrm{C} .,^{3}$ but at temperature'; below $15^{\circ}-20^{\circ} \mathrm{C}$. growth is restricted. ${ }^{2}$ The anaerobiosis essential for the growth of $\mathrm{Cl}$. welchii is provided by the meat or stew from which oxygen has been eliminated by cooking.

Fatalities due to $\mathrm{Cl}$. welchii food-poisoning among geriatric and debilitated patients in hospital are reported from time to time, but post-mortem findings are rarely

\footnotetext{
Public Health Laboratory Service, Mth. Bull. Mintst. Hlth Lab. Serv., 1962, 21, 180.

2 Barnes, E. M. Despaul, J. E., and Ingram, M., J. apd, Bact., 1963, 26, 415.

3 Collee, J. G., Knowlden, J. A., and Hobbs, B. C., ibid., 1961, 24. 326.

- Hobbs. B. C., Smith, M. E.. Oakley, C. L., Warrack, G. H., and Cruickshank, J. C., J. Hvg. (Lond.), 1953, 51, 75.

5 Dische. F. E., and Elek, S. D., Lancet, 1957, 2, 71

- McKillop, E. J., J. Hyg. (Lond.), 1959, 57, 31
} 